ISSN 0511-5728

The West Indian Journal of Engineering Vol.44, No.1, July 2021, pp.40-52

\title{
Advancing the Ultra High Frequency RFID in Industrial Applications: A Review
}

\author{
Tracy Aleong a, ${ }^{\mathrm{a}}$, and Kit Fai Pun ${ }^{\mathrm{b}}$ \\ Department of Mechanical \& Manufacturing Engineering, Faculty of Engineering, The University of the West Indies, \\ Trinidad and Tobago, West Indies; \\ aEmail: tracy.aleong1@gmail.com \\ bE-mail: KitFai.Pun@sta.uwi.edu \\ ${ }^{\Psi}$ Corresponding Author
}

(Received 13 March 2020; Revised 14 July 2021; Accepted 28 July 2021)

\begin{abstract}
Radio Frequency Identification (RFID) technology transmits data wirelessly and falls under the broad classification of Automatic Identification and Data Capture (AIDC). The advances in RFID technology continue to be accepted worldwide for various tracking and monitoring type applications. This paper reviews the principle of RFID system operation using an extensive search of relevant articles from technology management and related journals, over the past two decades. It 1) explores the RFID tags operating in the ultra-high frequency (UHF) band, 2) analyses some of the major advancements of this technology in the field of sensor tagging solutions in the past two decades, and 3) discusses industry-based applications utilising UHF RFID sensor tagging solutions for process measurement data acquisition. The main challenges identified are privacy and security concerns on their applications in industry. The paper contributes to amalgamating a list of UHF RFID industry-based applications. It is expected that the findings from this review exercise would shed light on critical areas of the UHF RFID Technology.
\end{abstract}

Keywords: RFID technology, UHF, automatic identification, industrial applications

\section{Introduction}

Radio Frequency Identification (RFID) is a wireless technology that allows for automated remote identification of objects, animals or persons (Ahmadian et al. 2005). Traditionally, RFID tags were used in applications such as tracking of inventory, assets, personnel, and manufacturing of goods and materials. While the adoption rate of RFID technology is increasing yearly, mass-market adoption is less likely unless some of the system challenges are addressed through the work of researchers and engineers in the associated fields of study.

In recent years, RFID system has combined the technology of smart sensors and the capability of global positioning system (GPS), which allows the possibility of acquiring sensor data including resistance measurement, temperature, vibration, pressure, movement and location to be wirelessly transmitted through such mediums as the internet of things (IoT). RFID like most other wireless technology has a lot of potential with continuous fast pace growth in some areas and at the same time can be considered provocative, with little to no progress in other areas. The integration of RFID technology with sensor technology opens the doors to developing other types of sensor RFID tags for monitoring process conditions, collecting valuable data for industry users.
This paper comprises five sections. Following the introduction section, it provides a brief overview of the RFID technology and the principle of operation for each of the components. It then describes the methodology used for the literature search and review and provides the quantitative analysis of literature along with the industry applications, recent advancements and limitations for use in the field of RFID Technology. The paper concludes with recommendations for future work, with a focus on UHF tags development and integration with Sensor tag technology.

\section{RFID Technology and Systems}

\subsection{A Brief History of RFID}

The early 20th century can be considered the birth of radar, a technology used to send out radio waves for detecting and locating an object by the reflection of the radio waves. One form of RFID is the combination of radio broadcast technology and radar. It is not unexpected that the convergence of these two radio disciplines and the thoughts of RFID occurred on the heels of the development of radar (Landt 2005). During World War II, the concept of the long-range transponder systems for "identification, friend, or foe" (IFF) used in aircraft was developed by the British and employed by the allies as a means to identify their fighter planes from the enemy. It relied on passive radar reflectors, tuned to the home radar frequency, which made a friendly aircraft 
much brighter to a home radar than an enemy aircraft (Chawla and Ha, 2007). The year 1948 earmarks a significant RFID technology paper published by Harry Stockman, "Communication utilising Reflected Power". This helped pave the way for further research and development within the field of study. Table 1 gives a summarised breakdown of the development of RFID technology over the decades starting from the 1940s to the twenty-first century.

Table 1: Historical breakdown of RFID Technology since the 1940s to date

\begin{tabular}{|c|c|}
\hline \multicolumn{2}{|r|}{ Decades of RFID } \\
\hline Decade & Event \\
\hline $\begin{array}{l}1940- \\
1950\end{array}$ & $\begin{array}{l}\text { - Radar refined and used major World War II } \\
\text { development efforts. RFID invented in } 1948\end{array}$ \\
\hline $\begin{array}{l}1950- \\
1960\end{array}$ & $\begin{array}{l}\text { - Early Exploration of RFID technology, lab } \\
\text { experiments }\end{array}$ \\
\hline $\begin{array}{l}1960- \\
1970\end{array}$ & $\begin{array}{l}\text { - Development of the theory of RFID. Field } \\
\text { application trials began } \\
\text { - In 1964, R.F. Harrington examines the } \\
\text { electromagnetic theory related to RFID in his paper } \\
\text { "Theory of Loaded Scatterers" } \\
\text { - The late 1960s saw the start-up of } 2 \text { companies called } \\
\text { Sensormatic and Checkpoint, working with another } \\
\text { company called Knogo, developing the Electronic } \\
\text { Article Surveillance (EAS) equipment to face the } \\
\text { theft of merchandise, an RFID based solution }\end{array}$ \\
\hline $\begin{array}{l}1970- \\
1980\end{array}$ & $\begin{array}{l}\text { - An explosion of RFID Development. Testing } \\
\text { accelerated with early adopter implementation of } \\
\text { RFID } \\
\text { - Between } 1973 \text { to 1975, large organisations Raytheon } \\
\text { and RCA developed electronic identification systems } \\
\text { - The 1970s showed RFID research being done by } \\
\text { laboratories and universities, such as the Los Alamos } \\
\text { Scientific Laboratory and Northwestern University } \\
\text { - In 1978, R.J. King published a book on microwave } \\
\text { homodyne techniques which would later be one of } \\
\text { the bases for the development of the theory and } \\
\text { practice which are used in backscatter RFID systems }\end{array}$ \\
\hline $\begin{array}{l}1980- \\
1990\end{array}$ & $\begin{array}{l}\text { - Commercial applications of RFID enter the } \\
\text { mainstream } \\
\text { - } 1987 \text { produced the first commercial application of } \\
\text { RFID, developed in Norway and later followed by the } \\
\text { Dallas North Turnpike in the United States in } 1989\end{array}$ \\
\hline $\begin{array}{l}1990- \\
2000\end{array}$ & $\begin{array}{l}\text { - The emergence of standards, RFID widely deployed, } \\
\text { used in everyday life applications } \\
\text { - In the '90s, a few American states such as Kansas and } \\
\text { Georgia implemented a traffic management system } \\
\text { that was based on the use of readers that could detect } \\
\text { protocol tags. Texas Instruments developed the } \\
\text { TIRIS system, which was used in applications related } \\
\text { to vehicle access. European companies, such as } \\
\text { Alcatel, Bosch and Phillips spin-off companies, such } \\
\text { as Combitech, Tagmaster and Baumer were involved } \\
\text { in the development of a pan-European standard for } \\
\text { tolling applications. These companies helped develop } \\
\text { a common standard for electronic tolling }\end{array}$ \\
\hline $\begin{array}{l}2000- \\
\text { Present }\end{array}$ & $\begin{array}{l}\text { - RFID continues to grow rapidly with increases in } \\
\text { R\&D. }\end{array}$ \\
\hline
\end{tabular}

Sources: Landt (2005) and Domdouzis, Kumar, and Anumba (2007)

RFID belongs to a group of technologies referred to as Automatic Identification and Data Collection (AIDC). AIDC methods automatically identify objects, collect data about them, and enter those data directly into computer systems with little or no human intervention (Patil and Patil 2018). Similar to RFID, traditional barcoding technology provides an economical solution for AIDC industry applications. However, this technology has a primary limitation: each barcoded item must be scanned individually, thus limiting the scanning speed. Extra costs are incurred through the use of manual labour or automating the scanning process. When scanning is manually performed, there is the added possibility of human error.

Because of these limitations, RFID technology is making inroads in AIDC applications worldwide. RFID offers greater flexibility, higher data storage capacities, increased data collection throughput, along greater immediacy and accuracy of data collection.

\subsection{The RFID System Architecture}

The RFID system architecture comprises of two main components; these are 1) the tag or transponder, which is usually attached to an object, and 2) a reader or interrogator. The reader is typically connected to a host computer where data is transferred and stored. Both components have an antenna; for the tag's antenna, it is internally installed within the tag encapsulation and for the reader, it can either be integrally mounted (a part of the device) or remote mounted (separate but connected via cable). The reader emits a radio signal at a fixed frequency, which is used to power up the tag, and communicates with it using a technique called backscattering (Chawla and Ha 2007; Tedjini and Perret 2009; Kaur et al. 2011). Figure 1 shows the core components of RFID, and the key components are elaborated on below.

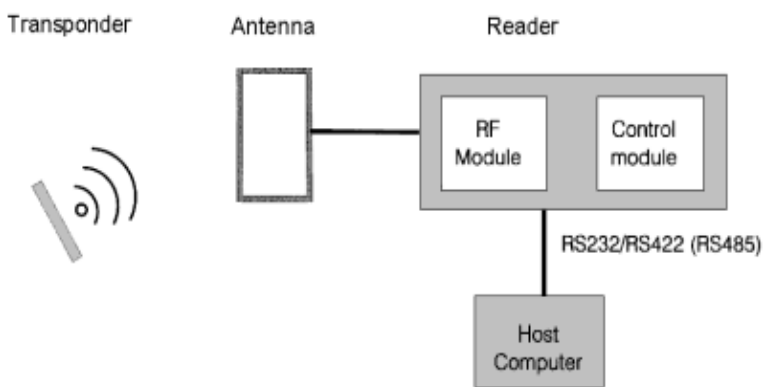

Figure 1. Components of RFID

\subsubsection{The RFID Tag}

An RFID tag in its most simplistic form comprises of three parts; an antenna for transmitting and receiving signals; an RFID chip (or integrated circuit, IC) which stores the tag's ID and other information; and lastly, some form of encapsulation (Hossain and Karmakar 2006; Want 2006). The tag encapsulation or housing composed of protective material maintains the tag's integrity and protects the antenna and chip from 
environmental conditions or reagents. The protective material used is mainly plastic and sometimes glass depending on the application requirements. The plastic housing was developed for applications involving particularly high mechanical demands where the tag is embedded between the layers of plastic.

RFID tags transmit data about an item through a specific radio frequency on the electromagnetic spectrum of waves to the antenna/reader combination. Within this spectrum, there are three (3) primary frequency ranges for RFID transmission - Low Frequency (LF), High Frequency (HF), and Ultra-High Frequency (UHF). Recently a 4th range has been added that exceeds the UHF range and it is commonly referred to as the Microwave range. Each frequency has different characteristics such as operating frequency range, read range (distance) and application suitability (appendix 1). The signal received by the reader is in the form of radio waves which is then converted to a usable form of data. Information collected from the tags can be transferred through a communications interface onto a host computer system, where the data can be stored and further analysed. RFID tags come in a variety of shapes and sizes and classified as either Active tags (batterypowered) or Passive tags (no internal power source). Passive tags are used more since they are smaller, thinner and less expensive to implement. These tags also have an indefinite operational life and are small enough to fit into a practical adhesive label (Want 2006).

An Active RFID tag has an on-board power supply (e.g., a battery) to broadcast data, either as a transponder replying to a signal or as a beacon, actively sending out its information. Active tags are mainly used in the UHF tag version since the battery affords long read ranges and large memory in exchange for a large form factor and a shorter lifespan. The battery can also power internal sensors designed to detect process parameters such as moisture, temperature and other environmental changes. In comparison, Active tags are more expensive than Passive tags due to battery maintenance and replacement. For this reason, the low cost of Passive tags makes them an ideal option for disposable and limited use applications. With the integration of sensor technology with RFID technology, a cross between active and passive tags was developed and it is commonly referred to as Battery-Assisted Passive (BAP) RFID tag. These BAP tags use an internal battery to power a sensor monitor and record the data periodically. They do not actively send a signal, instead only send it when requested by an RFID reader. Compared to Active tags, they are less costly and smaller in design since the battery has a smaller footprint.

Unlike Active tags, Passive tags do not have internal power sources and must rely on an external source to be "powered up". This is achieved by the electromagnetic field (EMF) created by the RFID reader. When the tag receives the transmission from the reader/antenna, the tag's antenna captures coupled energy from the EMF and transfers the tag's ID (the tag's IC coordinates this process). The coupled energy is rectified and the voltage multiplied via a multistage Greinacher half-wave rectifier to power up the IC. The energised chip modulates the energy with the desired information and then transmits a signal back towards the antenna of the reader (Kaur et al. 2011). For the energy coupling, there are two (2) different techniques used in passive tags; near-field and far-field coupling (Chawla and Ha, 2007; Kaur et al., 2011).

Because the inductive coupling or backscattered radio waves in $\mathrm{RF}$ identification is used to detect the physical parameters of tagged objects, it can be used to deal with sophisticated problems, for instance, to discriminate the variation of materials as a transmission medium of the radio waves. Therefore, RFID tags are also innovatively used as electromagnetic sensors for different measurement purposes, such as strain detection, material corrosion analysis, crack detection and food quality evaluation (Meng and Li 2016). In the case of the Passive RFID sensor tag, RF energy is harvested from the $\mathrm{RF}$ radiation to power the circuit and complete the sensing.

Due to their relatively low cost and large distance of communication, passive UHF tags are very promising, Tedjini et al. (2010) contend that UHF RFID technology is generating much interest in industrial and academic institutions owing to its immense potential in tracking. This is why the design of UHF RFID tags with high performances, low cost and interoperability is a very active field of research. Interoperability is needed since there are variations in the frequency bands worldwide (Finkenzeller, 2003; Weis, 2007). In practice, the emission limit is imposed as the equivalent isotropically radiated power (EIRP), defined as the product of the power accepted by the transmit antenna and its maximum gain over all the spatial angles within the regulated frequency band. For passive tags, the read range is dependent on the amount of power received in the transmission and for passive tags, it is important to refer the achieved read range to a specific EIRP value. Table 2 shows a list of the EIRP regulations for UHF RFID systems in different regions.

Table 2. EIRP Regulations for UHF RFID Systems in Different Countries

\begin{tabular}{|c|c|c|}
\hline $\begin{array}{c}\text { Countries/ } \\
\text { Regions }\end{array}$ & $\begin{array}{c}\text { Frequency Band } \\
{[\mathrm{MHz}]}\end{array}$ & $\begin{array}{c}\text { Effective Isotropic } \\
\text { Radiated Power, EIRP [W] }\end{array}$ \\
\hline Europe & $865.6-867.6$ & 3.28 \\
\hline China & $840.5-844.5$ & 3.28 \\
& $920.5-924.5$ & 4 \\
\hline Republic of & $817-920.8$ & 0.2 \\
Korea & $917-923.5$ & 4 \\
\hline Japan & $852-956.4$ & 4 \\
\hline Canada & $902-828$ & 4 \\
\hline United States & $902-828$ & 4 \\
\hline Australia & $820-926$ & 1 \\
\hline
\end{tabular}

Source: https://rfid4u.com/rfid-regulations/ 
The two options for powering the tags can be through an internal supply such as a battery or power derived from an electromagnetic field provided by the appropriate frequency reader. Simultaneously the way the tag is powered classes it as either an Active tag (battery-powered) or Passive tag (no internal power). The tag has within it, an IC and an antenna surrounded by the encapsulation for protecting the internal parts. Because tags come in different operating frequencies (such as LF, HF, UHF, Microwave), the tag must be chosen to meet the application's requirements. The second component in any RFID system is the reader, and its main purposes are to communicate with the field tag, provide power through electromagnetic induction and retrieve its stored data. This data is then transferred to a host system such as a computer where it can be stored for future processing.

\subsubsection{Readers}

The reader plays a crucial role as it can be considered the brain of the RFID system, managing the communication through synchronisation of transfers and other system functions. A Reader also referred to as an interrogator or transceiver device is used to transmit and receive radio waves to communicate with RFID tags. The main function of a reader is to collect the data stored in the tag (Tedjini and Perret, 2009). The reader emits radio waves in ranges of one (1) inch to one hundred (100) feet or more, depending upon its power output and the radio frequency. When an RFID tag passes through the electromagnetic zone, it detects the reader's activation signal. The reader decodes the data encrypted in the tag's IC (silicon chip) and the data is passed to the host computer for storage or processing (Elmorshidy 2010). The second main function of the reader is to write information into the tag. In addition to this ability to code and decode the information between the tag, the reader ensures the link to middleware that is specific to the application and its physical environment (Tedjini and Perret, 2009).

There are two (2) types of readers available, namely, Fixed RFID Readers and Mobile RFID Readers. Fixed readers usually stay in one location (such as mounted onto a wall), while mobile readers are usually handheld devices that are easily transported around and capable of maintaining wireless communication with a host computer or smart device. Fixed RFID Readers have a lot of flexibility when coupled with a multiplexer allowing additional ports for more antennas, thereby allowing larger coverage or read area. Simple applications may require just one antenna such as scanning in and out of a building, while other applications in the field of inventory and asset tracking in a large warehouse would need a bigger read zone (atlasRFIDstore 2019). In environments with many tags, a reader may have to perform an anti-collision protocol to ensure that communication conflicts do not occur.
Anti-collision protocols permit readers to rapidly communicate with many tags in serial order (Weis, 2007).

\subsubsection{RFID Antenna}

In an RFID system, the antenna plays a pivotal role in both the tag and the reader (Hossain and Karmakar 2006). Infinite varieties of antenna design are possible that provide optimal performance such as the covered slot antenna design presented by Chen and Hsu (2004) and the circular patch antenna analysis by Padhi et al. (2003) and Penttilä et al. (2006). Some of the others identified are Marrocco (2003) meander antenna optimisation, Hirvonen et al. (2004) planar inverted Fantenna, and Qing and Yang (2004) folded dipole antenna design. In each case, the designs were well presented but lacked an overview of criteria for RFID tag antenna design and analysis of practical application aspects. This was not the case of Nikitin and Rao (2009) who was able to cover the antenna design for passive UHF RFID tags, as well as providing a potential generic design process that covers range measurement techniques and then applied it to a practical application, i.e. RFID tag for box tracking in the warehouse.

In the simplest form, an RFID system has two main elements; the tag and the reader Figure 2 shows the Antenna Downtilt and Coverage Calculator (aka Antenna Tilt Angle Calculator) that is used to determine the approximate downward angle, measured in degrees, which the transmitting antenna is to be positioned for optimal signal strength and coverage. It also provides, given a beamwidth, the inner and outer radii of beam's coverage (https://www.microwavejournal.com).

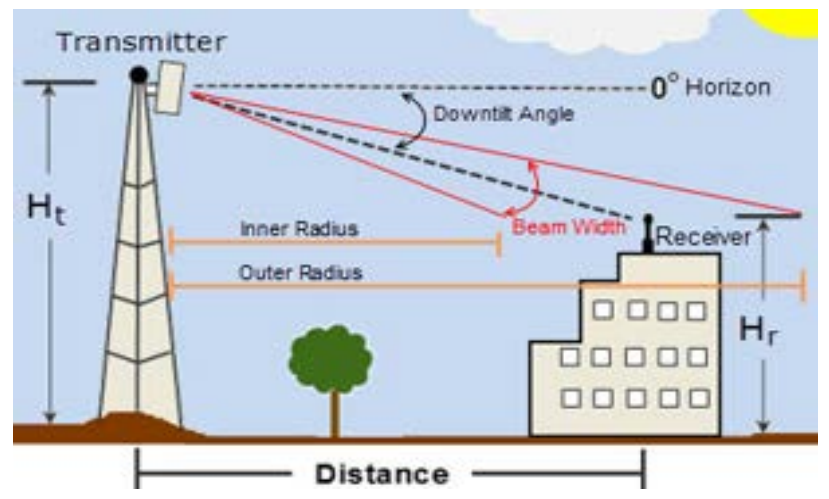

Figure 2. Antenna Downtilt and Coverage Calculator Source: https://www.microwavejournal.com/articles/29437-antennadesign-analysis-and-simulation

For readers, antennas are either integrated or built into the device or can be standalone and mounted separately from the reader. The reader provides power to the antennas, which then generates an RF field and synchronously, an RF signal is transmitted to the tags 
within the read range. The antenna's gains refer to the specific direction and strength in which waves are generated. Therefore, the higher the gain, the more powerful and further-reaching RF field an antenna would have. These generated waves are given off along a horizontal or vertical plane, which is considered the antenna's polarity. For passive tags, the tag antenna should receive the EM signal from the reader at a right angle to optimise performance since generally the tag antenna is omnidirectional (Hossain and Karmakar 2006).

Similar to the gain, the antenna's polarity affects the read range since a difference in polarities between the antenna of the reader and the RFID tag would significantly reduce the read range. If the polarities align, then the user can achieve the maximum read range. There is a circularly polarised antenna, which transmits waves in continuous rotation between horizontal and vertical planes, allowing an application enhanced flexibility, so RFID tags can be read in multiple orientations. The drawback of this type is still a shorter read range versus a similar gain linear antenna since the energy is divided between two planes (atlasRFIDstore, 2019).

\subsection{Principles of RFID Technology and Operations}

Kaur et al. (2011) offer a brief introduction to the principles of the technology, major current applications and challenges of deploying this technology. In terms of applications and usage, RFID has been widely applied for access control and information tracking in logistics and industrial processes (Meng and Li 2016). It is also considered as emerging and disruptive compact wireless and eminent enabling technology for the realisation of ubiquitous monitoring in ad hoc wireless networks especially if fused with other networks (Lakafosis et al. 2010). Since the inductive coupling or backscattered radio waves in RF identification can be used to detect the physical parameters of tagged objects (temperature, gas, moisture, etc.), the technology is also a potential solution for structural-health monitoring systems to detect the strains and cracks in aerospace, civil, or architectural structures, as well as in precision agriculture (Dey, Saha, and Karmakar 2015).

RFID has its list of limitations where security and privacy concerns top the list. Juels (2006) offers a general survey of the security and privacy issues related to RFID, while Mutigwe, Aghdasi, and Kinyua (2013) propose a solution of authenticated readers used to achieve RF silence thereby addressing the concerns raised by privacy advocates. Likewise, Engberg et al. (2004) proposed a "zero-knowledge" RFID security and privacy protocol where the tag only speaks to authenticated readers but did not provide adequate details on how the protocol would be managed. Every year, researchers and engineers have been finding new and useful applications for RFID systems (Finkenzeller,
2003). An increasing number of companies in a variety of markets worldwide are embracing RFID technology to increase the quality and quantity of data collection expeditiously.

\section{Literature Searches and Identification}

For this study, the data was acquired via searches conducted through Google Scholar. Material published between the years 2000 to 2019 was collected and stored for further analysis.

An advanced search criterion was performed with the terms "RFID" and "Radio Frequency Identification" located within the Title of the article that produced 2,073 various articles. With such a wide selection of articles under the main topic, subcategories of search phrases were used to narrow the selection process. These were:

1) RFID system principle of operation,

2) Ultra-High Frequency RFID,

3) Advancements in UHF RFID sensor tags technology, and

4) UHF RFID sensor tag in industrial applications.

\section{Findings and Analysis}

\subsection{RFID by Publication Date and Type}

Of 2,073 publications acquired for the period 2000-2019, 145 were of journal sourced, 2 of magazine sourced, 4 book sourced, 877 fell under reports/dissertation/working paper/other and 1,045 were patents and citations. Appendix 1 presents results by year for each category except citations and patents. Besides, Figure 3 depicts the results of the advanced search and it is well noted that in the period 2000 to 2003, it shows very little published on the topic of RFID. However, from 2004 there is a sudden increase in published articles with steady growth in numbers every 2 to 3 years. Although the numbers fluctuate most years, the overall trend is increasing publications, with the highest seen for the year 2014. The information recorded for the year 2019 shows a reduction from the previous year.

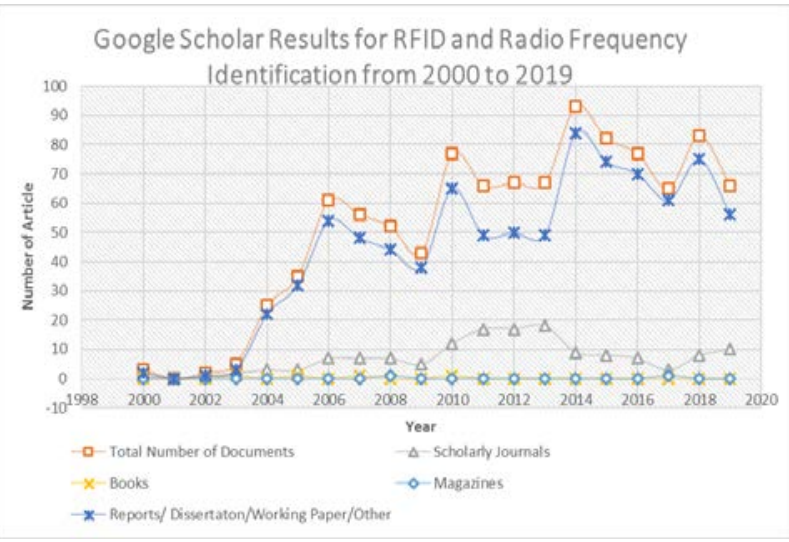

Figure 3. Google Scholar Results for RFID for the period 20002019 


\subsection{RFID Data by Sub-topic Areas}

To develop the data required to build the sections within this report, Sub-topic areas were researched. Tables 3-6 depict the organisation and analysis of four (4) sub-topic fields towards building the literature concepts and themes. These are:

1) RFID principle of operations,

2) Recent advancements in UHF RFID technology integrated with sensor tags,

3) Industrial applications for UHF RFID sensor tags, and
4) Major limitations in the field of RFID sensor tag technology.

\subsection{Recent Advancements on UHF RFID Tag Systems}

In recent times, researchers and engineers have integrated RFID tags with sensors capable of measuring environmental factors such as temperature and pressure. Dey, Saha, and Karmakar (2015) propose these sensor tags are smart sensing since they operate with wireless data-capturing technique that utilises RF energy to automatically extract the identity of remotely placed objects.

Table 3. Understanding of RFID Systems

\begin{tabular}{|c|c|c|c|}
\hline Concept & Notes & Author/Source & Interpretation of Viewpoint \\
\hline $\begin{array}{l}\text { Overview of } \\
\text { RFID }\end{array}$ & A most comprehensive overview of the topic. & Finkenzeller (2003). & $\begin{array}{l}\text { Delivers a general } \\
\text { understanding of the working } \\
\text { RFID System. }\end{array}$ \\
\hline $\begin{array}{l}\text { History of } \\
\text { RFID }\end{array}$ & Summaries main event in the past century for RFID Technology & $\begin{array}{l}\text { Domdouzis, Kumar, } \\
\text { and Anumba (2007) }\end{array}$ & $\begin{array}{l}\text { Use to build a history of } \\
\text { RFID }\end{array}$ \\
\hline Tag Design & $\begin{array}{l}\text { An RFID tag in its most simplistic form comprises of three parts; an } \\
\text { antenna for transmitting and receiving signals, and an RFID chip (or } \\
\text { integrated circuit, IC) which stores the tag's ID and other information } \\
\text { and some form of encapsulation }\end{array}$ & Want (2006) & Identifies the tag components \\
\hline Tag Design & $\begin{array}{l}\text { The tag encapsulation composed of a protective material maintains the } \\
\text { tag's integrity and protects the antenna and chip from environmental } \\
\text { conditions or reagents. The protective material depends on the } \\
\text { application. For example, employee ID badges containing RFID tags } \\
\text { are typically made from durable plastic, and the tag is embedded } \\
\text { between the layers of plastic }\end{array}$ & $\begin{array}{l}\text { Hunt, Puglia, and } \\
\text { Puglia (2007); } \\
\text { Finkenzeller (2010) }\end{array}$ & $\begin{array}{l}\text { Identifies the tag } \\
\text { components. Same as Want } \\
\text { (2006) }\end{array}$ \\
\hline Tag Design & $\begin{array}{l}\text { Its most simplistic form comprises of three parts: an antenna for } \\
\text { transmitting and receiving signals, and an RFID chip. The tag antenna } \\
\text { is generally omnidirectional }\end{array}$ & $\begin{array}{l}\text { Hossain and } \\
\text { Karmakar (2006) }\end{array}$ & $\begin{array}{l}\text { Identifies the tag } \\
\text { components. Same as Want } \\
(2006)\end{array}$ \\
\hline Antenna & The tag's antenna plays a pivotal role in both the tag and the reader & $\begin{array}{l}\text { Hossain and } \\
\text { Karmakar (2006) }\end{array}$ & $\begin{array}{l}\text { Talks about the antenna's } \\
\text { role }\end{array}$ \\
\hline RFID Readers & $\begin{array}{l}\text { Fixed RFID Readers have a lot of flexibility with the use of a } \\
\text { multiplexer to allow additional antenna ports, additional antennas can } \\
\text { be installed giving larger coverage or read area. }\end{array}$ & $\begin{array}{l}\text { atlasRFIDstore } \\
\text { (2019) }\end{array}$ & Discusses the Reader \\
\hline $\begin{array}{l}\text { Principle of } \\
\text { Operation }\end{array}$ & $\begin{array}{l}\text { It relied on passive radar reflectors, tuned to the home radar frequency, } \\
\text { which made a friendly aircraft much brighter to a home radar than an } \\
\text { enemy aircraft }\end{array}$ & $\begin{array}{l}\text { Chawla and Ha } \\
\text { (2007) }\end{array}$ & $\begin{array}{l}\text { Working principles of the } \\
\text { RFID system }\end{array}$ \\
\hline $\begin{array}{l}\text { Principle of } \\
\text { Operation }\end{array}$ & $\begin{array}{l}\text { AIDC methods automatically identify objects, collect data about them, } \\
\text { and enter those data directly into computer systems with little or no } \\
\text { human intervention }\end{array}$ & $\begin{array}{l}\text { Maruthaveni and } \\
\text { Kathiresan (2018) }\end{array}$ & $\begin{array}{l}\text { Working principles of the } \\
\text { RFID system }\end{array}$ \\
\hline $\begin{array}{l}\text { Principle of } \\
\text { Operation }\end{array}$ & $\begin{array}{l}\text { The main function of an RFID reader is to collect the data stored in the } \\
\text { tag }\end{array}$ & $\begin{array}{l}\text { Tedjini and Perret } \\
\text { (2009) }\end{array}$ & $\begin{array}{l}\text { Working principles of the } \\
\text { RFID system }\end{array}$ \\
\hline
\end{tabular}

Table 4. Major Advancements of the UHF RFID System within the Past 2 Decades in the Field of Sensor Tagging Solutions

\begin{tabular}{|c|c|c|c|}
\hline Concept & Notes & Author/Source & Interpretation of Viewpoint \\
\hline $\begin{array}{l}\text { Updates on } \\
\text { RFID } \\
\text { Technology }\end{array}$ & $\begin{array}{l}\text { One of the largest independent online forums providing the latest } \\
\text { news, case studies and insights on RFID technology business } \\
\text { applications }\end{array}$ & RFID Journal (2002) & $\begin{array}{l}\text { Can find many articles on } \\
\text { applications, industry users, } \\
\text { suppliers, advancements in } \\
\text { the field }\end{array}$ \\
\hline Applications & $\begin{array}{l}\text { Discusses major current applications and challenges of deploying this } \\
\text { technology }\end{array}$ & Kaur et al. (2011) & $\begin{array}{l}\text { The changes to RFID over } \\
\text { time is highlighted }\end{array}$ \\
\hline Advancement & $\begin{array}{l}\text { Considered as emerging and disruptive compact wireless and eminent } \\
\text { enabling technology for the realisation of ubiquitous monitoring in ad } \\
\text { hoc wireless networks especially if fused with other networks }\end{array}$ & $\begin{array}{l}\text { Lakafosis et al. } \\
\text { (2010) }\end{array}$ & Talks about potential uses \\
\hline
\end{tabular}


Table 4. Major Advancements of the UHF RFID System (continued)

\begin{tabular}{|l|l|l|l|}
\hline Concept & Notes & Author/Source & Interpretation of Viewpoint \\
\hline Advancement & $\begin{array}{l}\text { Since the inductive coupling or backscattered radio waves in RF } \\
\text { identification can be used to detect the physical parameters of tagged } \\
\text { objects, RFID technology is also a potential solution for smart sensing } \\
\text { to deal with some sophisticated problems }\end{array}$ & $\begin{array}{l}\text { Dey, Saha, and } \\
\text { Karmakar (2015) }\end{array}$ & $\begin{array}{l}\text { Talks about research in the } \\
\text { field of smart sensing }\end{array}$ \\
\hline $\begin{array}{l}\text { Design / } \\
\text { Advancements }\end{array}$ & $\begin{array}{l}\text { The design of UHF RFID tags with high performances and low cost is } \\
\text { a very active field of research }\end{array}$ & Tedjini et al. (2010) & Improvements to design \\
\hline $\begin{array}{l}\text { Operating } \\
\text { Frequency }\end{array}$ & Three frequency bands worldwide for UHF RFID Tags & Finkenzeller (2003) & $\begin{array}{l}\text { A few articles on this topic. } \\
\text { Information is similar. }\end{array}$ \\
\hline $\begin{array}{l}\text { Standard for } \\
\text { UHF }\end{array}$ & $\begin{array}{l}\text { Communication protocols for RFID are also being standardised and } \\
\text { currently, there is ISO 18000-6 standard that defines specifications for } \\
\text { RFID tags operating at UHF frequencies. }\end{array}$ & ISO (2004) & Recent additions \\
\hline $\begin{array}{l}\text { Standard for } \\
\text { UHF }\end{array}$ & $\begin{array}{l}\text { EPC Global standard defining the air interface protocol for RFID. In } \\
\text { addition, the most widely used tags follow the EPC global UHF Class } \\
\text { 1 Generation 2 standard which defines the physical and logical } \\
\text { requirements of the tags. }\end{array}$ & EPCglobal (2013) & Recent additions \\
\hline
\end{tabular}

Table 5. Industry-Based Applications Utilising UHF RFID Sensor Tagging Solutions for Process Measurement Data Acquisition

\begin{tabular}{|l|l|l|l|}
\hline Concept & Notes & Author/Source & Interpretation of Viewpoint \\
\hline Application & $\begin{array}{l}\text { RFID has been widely applied for access control and information } \\
\text { tracking in logistics and industrial processes }\end{array}$ & Meng and Li (2016) & $\begin{array}{l}\text { In terms of applications and } \\
\text { usage }\end{array}$ \\
\hline Application & $\begin{array}{l}\text { proposes these sensor tags are smart sensing since they operate with } \\
\text { wireless data-capturing technique that utilises RF energy to } \\
\text { automatically extract the identity of remotely placed objects }\end{array}$ & $\begin{array}{l}\text { Dey, Saha, and } \\
\text { Karmakar (2015) }\end{array}$ & Potential Application \\
\hline $\begin{array}{l}\text { New } \\
\text { applications }\end{array}$ & $\begin{array}{l}\text { RFID-enabled sensing platforms for cognitive intelligence applications } \\
\text { are introduced }\end{array}$ & Kim et al. (2013) & Advancements \\
\hline $\begin{array}{l}\text { New } \\
\text { applications }\end{array}$ & $\begin{array}{l}\text { Paper on the area of autonomous RFID-enabled wireless sensors, } \\
\text { focusing on low-power sensor nodes for use in temperature sensing } \\
\text { applications }\end{array}$ & $\begin{array}{l}\text { Dowling, Tentzeris, } \\
\text { and Beckett (2009) }\end{array}$ & Advancement \\
\hline
\end{tabular}

Table 6. Limitation of Using UHF RFID Systems

\begin{tabular}{|c|c|c|c|}
\hline Concept & Notes & Author/Source & Interpretation of Viewpoint \\
\hline $\begin{array}{l}\text { Security and } \\
\text { Privacy }\end{array}$ & A general survey of the security and privacy issues related to RFID & Juels (2006) & $\begin{array}{l}\text { Talks about concerns with } \\
\text { security and privacy for } \\
\text { using this technology }\end{array}$ \\
\hline $\begin{array}{l}\text { Solution to } \\
\text { Issue }\end{array}$ & $\begin{array}{l}\text { Proposed a "zero-knowledge" RFID security and privacy protocol } \\
\text { where the tag only speaks to authenticated readers but did not provide } \\
\text { adequate details on how the protocol works and managed }\end{array}$ & $\begin{array}{l}\text { Engberg, Harning, } \\
\text { and Jensen (2004) }\end{array}$ & $\begin{array}{l}\text { Proposal for a fix of privacy } \\
\text { concerns }\end{array}$ \\
\hline $\begin{array}{l}\text { Security and } \\
\text { Privacy }\end{array}$ & $\begin{array}{l}\text { Limited privacy protection in current RFID systems is a major concern } \\
\text { for individuals. further emphasises that RFID systems have become } \\
\text { synonymous with "insecure” systems, a situation that must be } \\
\text { thoroughly addressed before it severely limits the widespread } \\
\text { deployment of RFID systems }\end{array}$ & Zappone (2007) & Biggest concern \\
\hline $\begin{array}{l}\text { Other } \\
\text { Challenges }\end{array}$ & $\begin{array}{l}\text { Challenge of designing and developing communication protocols } \\
\text { consisting of a multi-layer authentication and encryption process for } \\
\text { data transfer between tag and reader }\end{array}$ & $\begin{array}{l}\text { Mutigwe, Aghdasi, } \\
\text { and Kinyua (2013) }\end{array}$ & \\
\hline $\begin{array}{l}\text { Operation } \\
\text { Challenge }\end{array}$ & $\begin{array}{l}\text { UHF readers may also interfere with sensitive electronics like medical } \\
\text { equipment }\end{array}$ & Weis (2007) & \\
\hline
\end{tabular}

\subsection{RFID-Enabled Sensor Tags and Industry Applications}

Traditionally, RFID sensors have been largely used in the field of asset tracking and inventory management type applications. The usages have grown into a multitude of applications covering a variety of domains (see Figure 4). In the case of inventory management, RFID rapidly replaced the barcode system as the need for scanning where line of sight proved to be time- consuming as opposed to RFID. For instance, applications of RFID systems are found in postal services to track packages and shipment locations; in manufacturing, to track parts delivery; tagging livestock, particularly cattle; retail item management; as a form of payment such as road tolls; security access and control to prevent unauthorised personnel from entering buildings or room without a swipe card. 


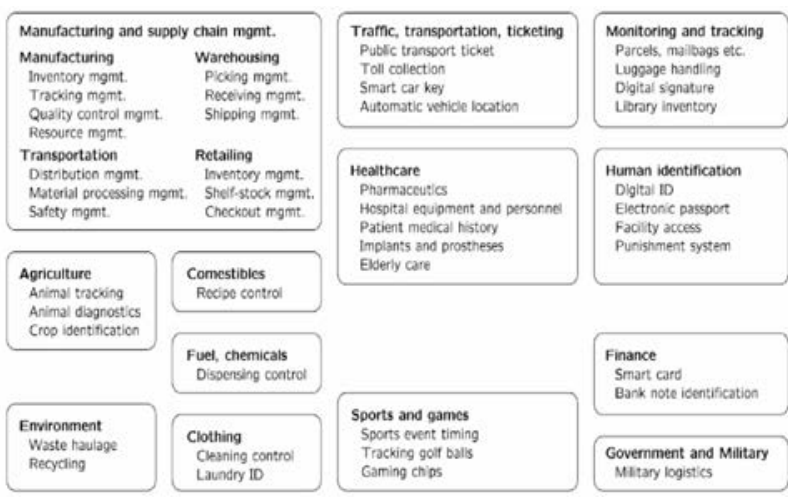

Figure 4. Applications of RFID Technology

Most recently, RFID tags have been integrated with electronic components, such as sensory material, Analogue-to-Digital Converter (ADC), and MicroController Unit (MCU) to make an integrated sensor module as in the case of pressure and temperature sensing tags (Meng and Li, 2016). Moreover, RFID sensors achieve measurement tasks in different ways and based on operating fundamentals, the related methods of RFID measurement can be classified into four categories: RFID electromagnetic sensor, RFID tag integrated sensor, RFID tag array, and RFID sensor networks. Table 7 presents the fundaments of measurement for each category.

Over the last decade, applications using RFIDenabled sensors have been investigated, with muchpublished work produced by various authors worldwide. Meng and Li (2016) summarise the application of RFID sensors and the measurable physical parameter as depicted in Figure 5.

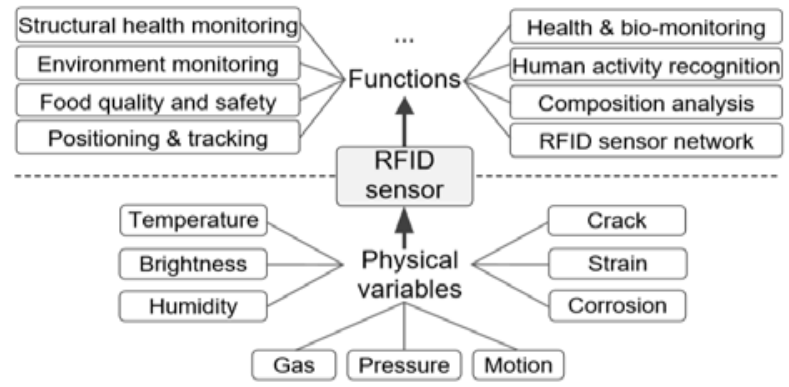

Figure 5. Applications of RFID Sensors Source: Abstracted from Meng and Li (2016)

Girbau et al. (2012) proposed an RF identification sensor system for temperature measurement comprising of passive resistive sensor and an ultra-wideband (UWB) reader. Similarly, Dowling et al. (2009) present a paper on the area of autonomous RFID-enabled wireless sensors, focusing on low-power sensor nodes for use in temperature sensing applications. Low-power chipless
RFID sensors operating in the $2.4 \mathrm{GHz}$ band are utilised. The sensors are required to be completely autonomous, energy-independent, inexpensive, and easy to install. For gas measurement, Potyrailo et al. (2009) investigate the combination of selective vapour sensors using organic electronic sensing materials with diverse response mechanisms to different vapours and passive RFID sensors with multivariable signal transduction. Another application looked at is the measurement of strain in different material compositions (Occhiuzzi, Paggi, and Marrocco 2011). Papers on using Ink-jet Printed RFID Sensor technology has also been published, for example, in monitoring water quality (Cook et al. 2013) and humidity (Virtanen et al. 2011).

Kim et al. (2013) discuss a variety of ink-jet-printed RFID-enabled sensor prototypes and perpetual RFIDenabled sensing platforms for cognitive intelligence applications introduction. Some clarity on the integration of RFID sensors with selected sensing materials such as water-absorbing materials for humidity sensors or carbon nanostructures for gas sensors to detect a parameter change is also given. The chemical, physical, or electrical reaction of the sensing materials in the presence of the sensed parameters would modify the electrical properties (permittivity, conductivity) resulting in easy-to-observe electrical metrics, such as a shift of the resonant frequency of the RFID tag antenna as shown in Figure 6, verifying the simplicity and power efficiency of RFID-enabled sensors.

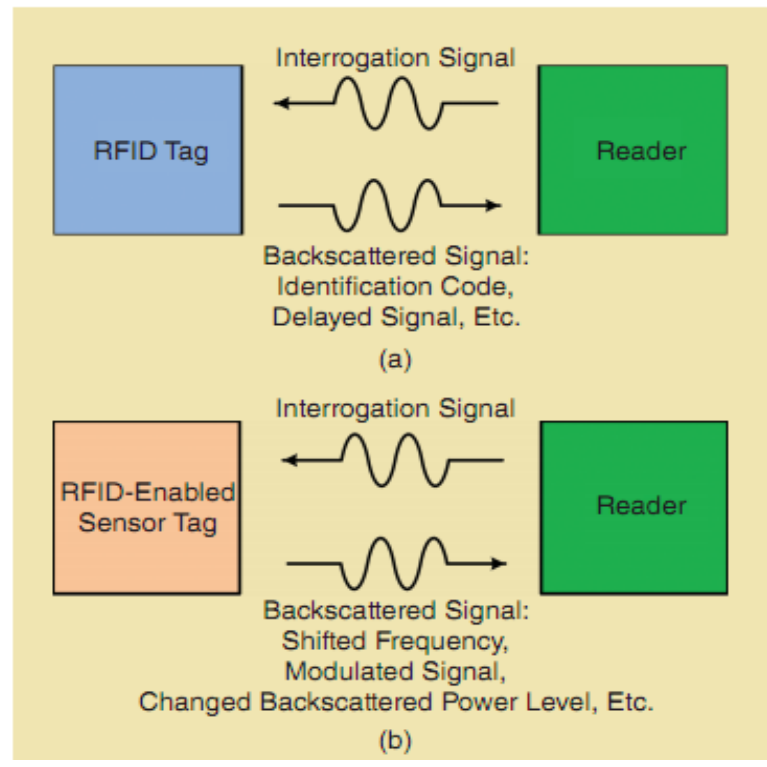

Figure 6. (a) RFID Tag and (b) RFID-enabled Sensor Tag

\subsection{Limitations of RFID Technology}

Although the uses of RFID systems have continuously grown over the past decades, the technology has been facing areas of concern limiting extensive diffusion into 
Table 7. Categories of RFID Sensor Measurement

\begin{tabular}{|l|l|}
\hline Categories & Fundamental of Measurement \\
\hline RFID electromagnetic sensor & $\begin{array}{l}\text { The normal passive RFID tag or chipless RFID, for which measurement is based on the analysis of its spectral } \\
\text { or phase characteristics }\end{array}$ \\
\hline RFID tag integrated sensor & Integrated with a sensor module, RFID is used for energy harvesting and data transmission \\
\hline RFID tag array & RFID array for expanding measurement space or for localisation and tracking \\
\hline RFID sensor networks & Batteryless and low-cost solution for wireless sensor networks monitoring \\
\hline
\end{tabular}

the wireless technology arena and practical adoption. A major hurdle is simply getting RFID systems to work in real-world environments. Systems that work perfectly in a laboratory setting may encounter problems when faced with environmental noise, interference, or human elements (Weis 2007). For example, simply repositioning or re-aligning readers would often address performance issues. Security and privacy issues are major areas of concern expressed for determining the suitability of this technology in different applications.

Zappone (2007) contends that limited privacy protection in current RFID systems is a major concern for individuals. He further emphasises that RFID systems have become synonymous with "insecure" systems, a situation that must be thoroughly addressed before it limits the widespread deployment of RFID systems. The problem lies within the radio-based mode of communication through detectable wireless channels. Therefore, some designs allow tags to promiscuously surrender their identity when queried by any reader operating at the appropriate frequency.

Traditional applications, like large-asset tracking, were typically closed systems and tags did not contain sensitive information. Tags on railway cars contained the same information painted on the side of the cars themselves. However, as more consumer applications emerged, so is the need for greater security and privacy protocols for using those systems. For the corporate executive, this privacy protection issue can leave the entire supply chain exposed to industrial espionage, while the security vulnerabilities can lead to counterfeiting and other acts of economic sabotage. In the last decade, many researchers have taken on the challenge of designing and developing communication security protocols in a bid to address these major concerns such as multilayer authentication and encryption for data transfer. One such study presented by Mutigwe, Aghdasi, and Kinyua (2013) proposes a design to meet this operation. Tuyls and Batina (2006) amongst others have gone further and proposed custom RFID cryptographic processors for this task. Avoine (2006) maintains a comprehensive bibliography of RFID security and privacy papers published by various researchers. below:

Several areas that pose challenges are indicated

1. Standardisation of Frequencies - Within the market exists different versions of RFID, operating at different frequencies. There is a need for interoperability agreements between manufacturers, retailers, and distributors and requires specific software and reader to work. This would reduce conflicts, such as, communication protocols, signal modulation types, data transmission rates, and data encoding for companies with closed-loop systems that want to promote their offerings.

2. Cost - The cost of Active tags is more than the cost of Passive tags due to the battery requirements. Consumers can opt to implement an alternative solution that might be more feasible for their operation. For instance, in the supply chain sector, barcoding of inventory is still the lower cost option for tagging goods as opposed to RFID tags.

3. Frequency - Choosing the optimal frequency depends on various factors, such as transmission mode and behaviour of tagged goods, read/receive distances, and the environment. Properties of some materials such as goods containing water or metal surface may be an obstacle to RFID application with the risk of signal absorption or reflections respectively at a given frequency, potentially leading to corrupted data transmission. Some materials have been developed that may shield UHF tags from metal-related distortion, but these may be cost-prohibitive to use in practice. UHF readers may also interfere with sensitive electronics like medical equipment (Weis 2007). Signal failure because of absorption and reflection can have possible solutions; failure at one frequency does not rule out applicability at other frequencies.

4. Social and legal issues - certain countries have restrictions on the allocation of the electromagnetic spectrum and may prohibit the use of these systems. There may be concerns about the health implications of continuous exposure to electromagnetic waves.

5. Data Collision - Attempting to read several tags at a time may result in a signal collision and ultimately to data loss. To prevent this, anti-collision algorithms (most of them are patented or patent-pending) can be applied but comes with a cost adder.

- RFID Data Cleansing - Despite the improvement of the accuracy of RFID readers, there are still erroneous readings such as missed reads and ghost reads, due to interference, temporary or permanent malfunction of system components. In addition, RFID data may contain significant redundant information due to duplicated readings. RFID data cleansing is therefore widely 
considered as a principal challenge and has been an important research topic in the last few years (Sheng et al. 2010).

- Global Standards - Similar to the concern of different existing frequencies, so is the concern here. Several standards of RFID systems are currently in use with the 2 most relevant being the International Organisation for Standardisation's ISO/IEC 18000 standard (ISO, 2004) and EPC Global standards (EPCglobal, 2013).

\subsection{Discussion}

\subsubsection{Findings for the research on RFID}

At present, the field of RFID research has abundant resources and published data for any researcher working in this area. Navigating the resource pool was at times, very tedious but eventually, a data pattern emerged from reviewing the various published articles. Within each piece, there was to some extent a simple introduction to the system and its associated components. RFID is considered a cost-effective option for wireless tracking and inventory management systems, as some of the tags are usually inexpensive.

The rate at which RFID is being accepted for different applications is constantly growing and associated with published data. Tracking and monitoring are traditional applications for this technology. While the greatest development pertains to the integration of RFID tags and sensor technology to create the sensor tag. These tags have great potential as industries can employ them in many applications. However, as many of the referenced authors mentioned, quite a few limitations prohibit the worldwide adoption of this system. With privacy and security topping the list of concerns, the implementation into many applications has to wait for an economical and viable fix to this issue.

\subsubsection{Significant Advancements in the Field of RFID Technology}

Process monitoring is an essential requirement of many industrial sites and the cost for specialised instrumentation can be expensive to implement. Instead, companies would limit the number of physical parameters monitored, such as temperature, pressure, strain, vapour emissions, and other process parameters. RFID sensor tag offers the world a cost-effective and simple architecture option for customers. In fact, with the wireless design and capabilities, many more application doors are opened which may have not been explored previously due to restrictions of having wired instruments. For instance, rotating equipment (such as fan blades) can be equipped with temperature and vibration tags. This would allow the maintenance team to acquire information from the moving parts of their equipment which was not possible with wired instruments.

The developments in tag, antenna, and reader designs have been noteworthy advancements. While improvements are important, researchers also have to continue keeping the cost down for the system to have a competitive edge over other existing wireless systems of similar performance. Within the past two decades, global standards have been created and implemented for RFID systems with the two most relevant and discussed being ISO 18000 and EPC Global standards. These standards would help streamline the processes used by the different manufacturers of RFID components to ensure product quality and assurances are met.

\subsubsection{Potentials for Implementing UHF RFID Sensor Tags in Industry}

To implement RFID systems into any application, it is advisable to have at least a basic understanding of how the RFID system works, specifically the principle of operations for the individual components. The feasibility of the application is another important factor, simple meaning if the application is suitable for using an RFID system. Noting the limitations such as security concerns, read range limits and asset material composition are just a few of the different aspects that can severely affect how effective an RFID system functions if installed. The Application Feasibility process should entail scoping of the project and the project's environment as a starting point, and then determining if RFID (or another technology) is the right fit for the application. Some simple questions to ask regarding the application to identify the most suitable tag design would be:

- What item is being tagged?

- How far would the tagged device be from the readers?

- How many tagged items or tags required?

- Does the tag require power or would the reader be able to provide the power source?

- What data needs to be collected from the tag? In other words, what are the data packets size and speed requirements between tag and reader?

- Are metal objects/surfaces near the tagged item?

- What are the size requirements for a tag?

Cost is another factor to consider when selecting RFID for an application. Cost for initial start-up (fixed cost) includes labour, training, and recurring costs such as maintenance of system, tag lifespan. In the case of Active tags, changing batteries periodically would be a recurring cost as opposed to Passive tags. In addition, considerations of other systems that may be more reliable and secure might outweigh the cost factor of RFID.

\section{Conclusion}

Today, RFID has become one established and applied technology with major advances in the field of smart sensing for everyday industry base process applications such as temperature and vibration. This significant development has attracted attention from researchers and 
engineers to the field as two of the major advantages of employing this system are Low-cost and Wireless Communications. In this paper, the principle of operations was discussed, as well as individual components and their associated roles. It is quite evident that many researchers would continue to push the bar by proposing new designs for various smart sensing applications. This is surely an imperative area for continued future developments and research (R\&D). As long as developments continue, this technology has the potential to become an integral part of people's daily lives.

Despite the obvious potential, several fundamental research and development issues persist. As long as privacy and security concerns are not addressed properly, the worldwide adoption of this technology would be affected. R\&D works continue in these and other areas such as passive tags, particularly the UHF tags. This is to ensure interoperability, low-cost maintenance requirements, and data security. An in-depth look into this area of concern will be conducted, analysed and submitted for review in a future study.

Of all the classes of tags, the UHF tag can meet most application requirements because it is considered to have a balance performance of range and readability as compared to the other frequency ranges of tags. However, there are disadvantages in using these tags such as susceptibility to interferences caused by environmental idiosyncrasies like metal distortion. When that happens, the signals might be absorbed or reflected if the tag is near metal. This would result in unreliable data transmission and can affect the future developments of the UHF passive tags in the smart sensory integration drive.

In other situations of interferences, the best way to address those issues would be by trial and error, and practical experience to recognise what is causing the problem. For example, simply repositioning or realigning readers would often address performance issues in some situations. It would be meaningful to conduct different tests and record the performance of UHF passive tags under varying environmental conditions especially in the tropical climate of sun, rain, and windy conditions.

One area for future research would be to extend the range and utility of wireless sensors especially the ones that are designed with passive tags. Other possible areas of research include energy harvesting and power scavenging of ambient energy sources, such as light, vibration, RF, and heat. The introduction of printed circuits also plays a promising role in future developments of tag design. If field application testing is successful, this advancement has the potential to greatly lower manufacturing costs and to produce RFID tags built out of flexible plastic materials, instead of other materials like silicon. This technology might be years away from being economic and there are many hurdles to overcome.
As the market continues to grow, certain aspects of the RFID system's costs would drop and new applications would become more economical. The prosperity of different kinds of RFID smart sensing technology is simple enough for this researcher and others alike to continue research within the field, which can one day lead to the worldwide technological adoption of this simple, yet practical solution.

\section{References:}

Ahmadian, M., Nazari, Z.J., Nakhaee, N., and Kostic, Z. (2005), Model based design and SDR", Proceedings of the 2nd IEE/EURASIP Conference on DSPenabledRadio (Ref. No. 2005/11086)

atlasRFIDstore (2019), “The Beginner's Guide to RFID Systems”, Available online at https://www.atlasrfidstore.com/rfidbeginners-guide/.

Avoine, G. (2006), "Bibliography on security and privacy in RFID systems”, Available online at lasecwww. epfl. ch/ gavoine/rfid 7.

Chawla, V., and Ha, D.S. (2007), “An overview of passive RFID”, IEEE Communications Magazine, Vol.45, No.9, pp.11-17.

Chen, S-Y., and Hsu, P. (2004), "CPW-fed folded-slot antenna for $5.8 \mathrm{GHz}$ RFID tags”, Electronics Letters, Vol.40, No.24, pp.1516-1517.

Cook, B.S., Cooper, J.R., Kim, S., and Tentzeris, M.M. (2013), “A novel inkjet-printed passive microfluidic RFID-based sensing platform", Proceedings of the 2013 IEEE MTT-S International Microwave Symposium Digest (MTT), IEEE, June, pp.1-3

Dey, S., Saha, J.K., and Karmakar, N.C. (2015), "Smart sensing: Chipless RFID solutions for the Internet of Everything”, IEEE Microwave Magazine, Vol.16, No.10, pp.26-39.

Domdouzis, K., Kumar, B., and Anumba, C. (2007), "RadioFrequency Identification (RFID) applications: A brief introduction”, Advanced Engineering Informatics, Vol.21, No.4, pp.350-355.

Dowling, J., Tentzeris, M.M., and Beckett, N. (2009), "RFIDenabled temperature sensing devices: A major step forward for energy efficiency in home and industrial applications?", Proceedings of the 2009 IEEE MTT-S International Microwave Workshop on Wireless Sensing, Local Positioning, and RFID, IEEE, September, pp.1-4

Elmorshidy, A. (2010), "Radio Frequency Identifiers: What are the Possibilities?”, arXiv preprint arXiv:1005.5129.

Engberg, S.J., Harning, M.B., and Jensen, C.D. (2004), “Zeroknowledge device authentication: Privacy and security enhanced RFID preserving business value and consumer convenience", PST, October, pp.89-101, available at: http://citeseerx.ist.psu.edu/viewdoc/download?doi=10.1.1.68.413 7\&rep=rep1\&type=pdf

EPCglobal (2013), "EPC radio-frequency identity protocols generation-2 UHF RFID; specification for RFID air interface protocol for communications at $860 \mathrm{MHz}-960 \mathrm{MHz}$ ", EPCglobal Inc., November.

Finkenzeller, K. (2003), RFID Handbook: Fundamentals and Applications, [electronic resource], available at: https:/onlinelibrary.wiley.com/doi/book/10.1002/0470868023

Finkenzeller, K. (2010), RFID Handbook: Fundamentals and Applications in Contactless Smart Cards, Radio Frequency Identification and Near-field Communication, John Wiley \& Sons.

Girbau, D., Ramos, A., Lazaro, A., Rima, S., and Villarino, R. (2012), "Passive wireless temperature sensor based on timecoded UWB chipless RFID tags", IEEE Transactions on Microwave Theory and Techniques, Vol.60, No.11, pp.36233632. 
Appendix 1: Characteristics for Tags Operating on the Different Frequencies (LF, HF, UHF, Microwave)

\begin{tabular}{|c|c|c|c|c|}
\hline Frequency Range & $\begin{array}{c}125 \mathrm{KHz} \\
\text { Low Frequency (LF) }\end{array}$ & $\begin{array}{c}13.56 \mathrm{MHz} \\
\text { High Frequency (HF) }\end{array}$ & $\begin{array}{c}868-956 \mathrm{MHz} \\
\text { Ultra-High Frequency } \\
(\mathrm{UHF}) \\
\end{array}$ & $\begin{array}{c}2.45 \mathrm{GHz} \& 5.8 \mathrm{GHz} \\
\text { Microwave }\end{array}$ \\
\hline $\begin{array}{c}\text { Typical Max Read } \\
\text { Range (Passive } \\
\text { Tags) }\end{array}$ & $<0.5 \mathrm{~m}$ & $\sim 1 \mathrm{~m}$ & $-3 m$ to $-10 m$ & $-1 \mathrm{~m}$ \\
\hline $\begin{array}{c}\text { General } \\
\text { Characteristics }\end{array}$ & $\begin{array}{l}\text { Relatively expensive, } \\
\text { even at high volumes. } \\
\text { Low frequency requires a } \\
\text { longer more expensive } \\
\text { copper antenna. } \\
\text { Additionally, inductive } \\
\text { tags are more expensive } \\
\text { than a capacitive tag. } \\
\text { Least susceptible to } \\
\text { performance } \\
\text { degradations from metal } \\
\text { and liquids }\end{array}$ & $\begin{array}{l}\text { Less expensive than } \\
\text { inductive low frequency } \\
\text { tags. Relatively short read } \\
\text { range and slower data } \\
\text { rates when compared to } \\
\text { higher frequencies. Best } \\
\text { suited for application that } \\
\text { do not require long range } \\
\text { reading of multiple tags }\end{array}$ & $\begin{array}{l}\text { In large volumes, UHF } \\
\text { tags have the potential for } \\
\text { being cheaper than LF } \\
\text { and HF tags due to recent } \\
\text { advances in IC design. } \\
\text { Offers good balance } \\
\text { between range and } \\
\text { performance; capable of } \\
\text { reading multiple tags } \\
\text { quickly }\end{array}$ & $\begin{array}{l}\text { Similar characteristics to } \\
\text { the UHF tag but with } \\
\text { faster read rates. A } \\
\text { drawback to this band is } \\
\text { that microwave } \\
\text { transmissions are the } \\
\text { most susceptible to } \\
\text { performance } \\
\text { degradations due to metal } \\
\text { and liquids, among other } \\
\text { materials }\end{array}$ \\
\hline Tag Power Source & $\begin{array}{l}\text { Generally passive tags } \\
\text { only, using inductive } \\
\text { coupling }\end{array}$ & $\begin{array}{l}\text { Generally passive tags } \\
\text { only, using inductive or } \\
\text { capacitive coupling }\end{array}$ & $\begin{array}{l}\text { Active tags with integral } \\
\text { battery or passive tags } \\
\text { using capacitive, E-field } \\
\text { coupling }\end{array}$ & $\begin{array}{l}\text { Active tags with integral } \\
\text { battery or passive tags } \\
\text { using capacitive, E-field } \\
\text { coupling }\end{array}$ \\
\hline $\begin{array}{c}\text { Typical } \\
\text { Applications Today }\end{array}$ & $\begin{array}{l}\text { Access control, animal } \\
\text { tracking, vehicle } \\
\text { immobilizers, POS } \\
\text { application including } \\
\text { SpeedPass }\end{array}$ & $\begin{array}{l}\text { Smart Cards, Item-level } \\
\text { tracking including } \\
\text { baggage handling (Non- } \\
\text { US), libraries }\end{array}$ & $\begin{array}{l}\text { Pallet tracking, electric toll } \\
\text { collection, baggage } \\
\text { handling (US) }\end{array}$ & $\begin{array}{l}\mathrm{SCM} \text {, electronic toll } \\
\text { collection }\end{array}$ \\
\hline Notes & $\begin{array}{l}\text { Largest install base due } \\
\text { to the mature nature of } \\
\text { low frequency, inductive } \\
\text { transponders }\end{array}$ & $\begin{array}{l}\text { Currently the most widely } \\
\text { available frequency } \\
\text { worldwide due mainly to } \\
\text { the relatively wide } \\
\text { adoption of smart cards; } \\
\text { common frequency } \\
\text { worldwide }\end{array}$ & $\begin{array}{l}\text { Different frequencies and } \\
\text { power levels are used } \\
\text { worldwide: Europe allows } \\
868 \mathrm{MHz} @ .5 \text { to } 2 \text { watts } \\
\text { whereas the US permits } \\
\text { operation at } 915 \mathrm{MHz} @ \\
4 \mathrm{w} \text {; Japan does not allow } \\
\text { transmissions in this band } \\
\text { at this time. }\end{array}$ & \\
\hline Data Rate & Slowest & $\leftarrow \cdots t \cdots$ & $\cdots \cdots+\cdots \rightarrow$ & Fastest \\
\hline $\begin{array}{l}\text { Ability to read near } \\
\text { metal or wet } \\
\text { surfaces }\end{array}$ & Best & $\leftarrow \cdots \cdot \mathrm{t} \cdots \ldots$ & 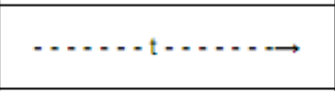 & Worst \\
\hline Passive Tag Size & Largest & $\leftarrow \cdots t \cdots \cdots$ & $\cdots \cdots+\cdots \rightarrow$ & Smallest \\
\hline
\end{tabular}

Hirvonen, M., Pursula, P., Jaakkola, K., and Laukkanen, K. (2004). "Planar inverted-F antenna for radio frequency identification", Electronics Letters, Vol.40, No.14, pp.848-850.

Hossain, M.D., Shahriar, S., and Karmakar, N. (2006), "An overview on RFID frequency regulations and antennas", Proceedings of the 2006 International Conference on Electrical and Computer Engineering, IEEE, December, pp.424-427

Hunt, V.D., Puglia, A., and Puglia, M. (2007), RFID: A Guide to Radio Frequency Identification. John Wiley \& Sons.

ISO (2004), ISO/IEC 18000-6: 2004 - Information technology Radio frequency identification for item management - Part 6: Parameters for air interface communications at $860 \mathrm{MHz}$ to 960 $\mathrm{MHz}$, available at https://www.iso.org/standard/34117.html.

Juels, A. (2006), "RFID security and privacy: A research survey", IEEE journal on selected areas in communications, Vol.24, No.2, pp.381-394.

Kaur, M., Sandhu, M., Mohan, M., and Sandhu, P.S. (2011), "RFID technology principles, advantages, limitations and its applications", International Journal of Computer and Electrical Engineering, Vol.3, No.1, pp.151

Kim, S., Mariotti, C., Alimenti, F., Mezzanotte, P., Georgiadis, A., Collado, A., Roselli, L., and Tentzeris, M.M. (2013), "No battery required: Perpetual RFID-enabled wireless sensors for cognitive intelligence applications”, IEEE Microwave Magazine, Vol.14, No.5, pp.66-77.
Lakafosis, V., Rida, A., Vyas, R., Yang, L., Nikolaou, S., and Tentzeris, M.M. (2010), "Progress towards the first wireless sensor networks consisting of inkjet-printed, paper-based RFIDenabled sensor tags", Proceedings of the IEEE, Vol.98, No.9, pp. 1601-1609.

Landt, J. (2005), “The history of RFID”, IEEE Potentials, Vol.24, No.4, pp.8-11.

Marrocco, G. (2003), "Gain-optimised self-resonant meander line antennas for RFID applications”, IEEE Antennas and Wireless Propagation Letters, Vol.2, pp.302-305.

Maruthaveni, R., and Kathiresan, V. (2018), "A critical study on RFID”, International Journal of Scientific Research in Network Security and Communication, Vol.6, No.2, pp.62-65.

Meng, Z., and Li, Z. (2016), "RFID Tag as a Sensor-a review on the innovative designs and applications", Measurement Science Review, Vol.16, No.6, pp.305-315.

Mutigwe, C., Aghdasi, F., and Kinyua, J. (2013), “A scalable, privacy-preserving and secure RFID protocol”, International Journal of Engineering and Technology, Vol.5, No.2, pp.237

Nikitin, P.V, and Seshagiri Rao, K.V. (2009), "LabVIEW-based UHF RFID tag test and measurement system", IEEE Transactions on Industrial Electronics, Vol.56, No.7, pp.23742381.

Occhiuzzi, C., Paggi, C., and Marrocco, G. (2011), "Passive RFID strain-sensor based on meander-line antennas", IEEE 
Transactions on Antennas and Propagation, Vol.59, No.12, pp.4836-4840.

Padhi, S.K., Karmakar, N.C., Law, C.L., and Aditya, S. (2003), “A dual polarised aperture coupled circular patch antenna using a Cshaped coupling slot”, IEEE Transactions on Antennas and Propagation, Vol.51, No.12, pp.3295-3298.

Patil, H.J., and Patil, D.T. (2018), "Internet of Things and its application to the libraries", Internet of Things and Current Trends in Libraries, Vol.12, pp.21-25

Penttilä, K., Keskilammi, M., Sydänheimo, L., and Kivikoski, M. (2006), "Radio frequency technology for automated manufacturing and logistics control. Part 2: RFID antenna utilisation in industrial applications", International Journal of Advanced Manufacturing Technology, Vol.31, Nos.1-2, pp. 116124.

Potyrailo, R.A, Surman, C., Go, S., Lee, Y., Sivavec, T., and Morris, W.G. (2009), "Development of radio-frequency identification sensors based on organic electronic sensing materials for selective detection of toxic vapors", Journal of Applied Physics, Vol.106, No.12, pp.124902.

Qing, X., and Yang, N. (2004), "A folded dipole antenna for RFID”, Proceedings of the IEEE 2004 Antennas and Propagation Society Symposium, IEEE, June, pp.97-100

Sheng, Q.Z, Zeadally, S., Luo, Z., Chung, J-Y., and Maamar. Z. (2010), “Ubiquitous RFID: Where are we?” Information Systems Frontiers, Vol.12, No.5, pp.485-490.

Tedjini, S., and Perret, E. (2009), "Radio-frequency identification systems and advances in tag design”, URSI Radio Science Bulletin, Vol.331, pp.9-20.

Tedjini, S., Perret, E., Deepu, V., and Bernier, M. (2010), "Chipless tags, the next RFID frontier", In: The Internet of Things, Springer, p.239-249.

Tuyls, P., and Batina, L. (2006), RFID-Tags for Anticounterfeiting, CT-RSA 2006, LNCS 3860. Springer-Verlag.
Virtanen, J., Ukkonen, L., Bjorninen, T., Elsherbeni, A.Z., and Sydänheimo, L. (2011), "Inkjet-printed humidity sensor for passive UHF RFID systems", IEEE Transactions on Instrumentation and Measurement, Vol.60, No.8, pp.2768-2777.

Want, R. (2006), An Introduction to RFID Technology, IEEE Pervasive Computing. Jan.

Weis, S.A. (2007), "RFID (radio frequency identification): Principles and applications”, System, Vol.2, No.3, pp.1-23.

Zappone, C. (2007), "Backlash against RFID is growing", Cable News Network, Accessed Feb. https://money.cnn.com/2007/05/21/technology/rfid/index.htm.

\section{Authors' Biographical Notes:}

Tracy Aleong is a Director of Smart Technical Process Solutions Limited, Trinidad. She has substantial work experience in process plant instrumentation engineering, controls and automation. Ms. Aleong received her B.A.Sc. in Electrical Engineering from the University of Trinidad and Tobago, Trinidad and Tobago and her MBA specialised in Innovation and Leadership from Anglia Ruskin University, United Kingdom. She is currently pursuing an MPhil in Industrial Engineering at The University of the West Indies, Trinidad and Tobago. Her research interest and activities include industrial engineering, smart instrumentation technology, mass local manufacturing and graphical designs.

Kit Fai Pun is presently Professor of Industrial Engineering of the Faculty of Engineering at The University of the West Indies, St Augustine Campus, Trinidad and Tobago. He is a Registered Professional Engineer in Australia, Europe, Hong Kong, and The Republic of Trinidad and Tobago. His research interests and activities include industrial engineering, engineering management, quality systems, and performance measurement. 